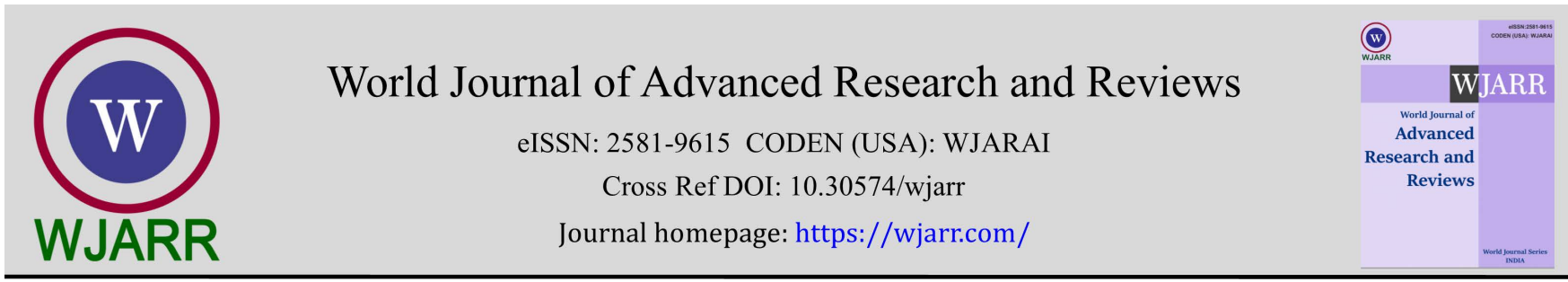

(REVIEW ARTICLE)

Check for updates

\title{
Covid-19 and food security: Jeopardy management and posterity deliberations
}

\author{
Augustine Owusu-Addo, Atianashie Miracle A*, Chukwuma Chinaza Adaobi and Larissa Agbemelo-Tsomafo \\ Catholic University College of Ghana, Fiapre Sunyani, Bono Region, Ghana.
}

World Journal of Advanced Research and Reviews, 2021, 10(02), 001-005

Publication history: Received on 21 March 2021; revised on 30 April 2021; accepted on 03 May 2021

Article DOI: https://doi.org/10.30574/wjarr.2021.10.2.0183

\begin{abstract}
COVID-19, also known as the 'novel coronavirus disease 2019', is a respiratory illness and the causative pathogen is officially named as 'SARS-CoV-2'. Infections with SARS-CoV-2 have now been amplified to a global pandemic - as of April 3,2020 , nearly 1,018,000 cases have been confirmed in more than 195 countries, including more than 300,000 cases within the United States. Public safety guidelines are followed worldwide to stop the spread of COVID-19 and stay healthy. Despite COVID-19 is a respiratory illness with mode of invasion through the respiratory tract, not the gastrointestinal tract, an average food consumer is anxious and concerned about the food safety. Could an individual catch the deadly contagious COVID-19 from groceries brought home from the supermarket - or from the next restaurant takeout order? This brief review elucidates the epidemiology and pathobiological mechanism(s) of SARS-CoV-2 and its implications in food-borne infections, transmission via food surfaces, food processing and food handling.
\end{abstract}

Keywords: SARS-CoV-2; Food security; COVID-19; Infection and transmission; Posterity deliberations

\section{Introduction}

The first cases of COVID-19 were reported in November 2019 in the province of Hubei, China. Since 23 January 2020 , the city of Wuhan has been locked down. Quite soon afterwards, other areas of China adopted very strict measures to contain the spreading of COVID-19. Now, China claims effective control over the spread of COVID-19. However, the impacts, both on China (about two months of disruption/strong negative influence on production) and on the world (China's current proportion of World GDP stands at $16.3 \%$, compared to only $4.2 \%$ at the time of the SARS outbreak in 2003) are quite big and not yet fully estimated.

\section{Coronavirus (CoV) and SARS-CoV-2}

Coronavirus ( $\mathrm{CoV}$ ) belongs to a large family of viruses that cause illness ranging from the common cold to more severe diseases. CoVs are positive-stranded enveloped RNA viruses belonging to the order Nidovirales, classified into four genera: Alpha, Beta, Delta and Gamma. Two of the Beta-CoVs, the severe acute respiratory syndrome CoV (SARS-CoV) and the Middle East respiratory syndrome CoV (MERS-CoV), have caused serious epidemics worldwide. In December 2019, a novel CoV (SARS-CoV-2) emerged from Wuhan, China, and spread rapidly to a global proportion. (Deye, N., Vincent, F., Michel, P., Ehrmann, S., Da Silva, D., Piagnerelli, M., Laterre, P.-F. (2016). Changes in cardiac arrest patient's temperature management after the 2013 trial: Results from an international survey. Annals of Intensive et al., 2016) Although its original host remains unknown, all available data point to a wild animal source. This novel respiratory pathogen is the seventh CoV known to infect humans - the 3 viruses: SARS-CoV, MERS-CoV and SARS-CoV-2 can cause SARS illness; whereas, the remaining 4 viruses: HKU1, NL63, OC43 and 229E are associated with mild symptoms (WHO, 2019).

\footnotetext{
* Corresponding author: Atianashie Miracle A

Catholic University College of Ghana, Fiapre Sunyani, Bono Region, Ghana.
} 


\section{Chemistry and Pathobiology of SARS-CoV-2}

Viruses facilitate their replication cycle using three basic steps, attachment to the host cell, injection of genomic material into the host cell, and replication via the host cell genome mechanisms to form new virions. (Kamboj et al., 2020). The virulence of $\mathrm{CoV}$ is attributed to four structural proteins: Spike (S), Envelope (E), Membrane (M), and Nucleocapsid (N). Among these, S protein plays the critical role in viral attachment, fusion and entry. S protein is the 'hook' that mediates viral entry into host cells by first attaching to a host receptor through its receptor-binding domain (RBD) and then fusing the viral and host membranes through the S2 subunit.7 Both SARS-CoV and -CoV-2 recognize angiotensin-converting enzyme 2 (ACE2) as host binding receptor, which is an exopeptidase involved in blood pressure regulation. (Olaimat et al., 2020). These two key features of the S protein allow the virus to open and enter the host respiratory cells. The RBD in S protein of SARS-CoV-2 is the most likely target for the development of virus attachment inhibitors, neutralizing antibodies, and vaccines.

Mucosal epithelia including in the respiratory tract are coated with a layer of mucin polysaccharides (usually sulfated). Consequently, the polydisperse, natural products of heparan sulfate and the allied polysaccharide, heparin have been found to be involved in the pathobiology of CoV infection. Interestingly, several antimicrobial proteins such as lactoferrin, defensins and lysozyme that are native to the mucosal secretions are potential viral adhesion-blocking agents for providing the first-line defense among mammals, including humans. (Chan \& Ma, 2020). Elucidating the viral attachment/detachment mechanisms is key to understand the interactions of SARS-CoV-2 with different food matrices and to develop nutraceutical interventions to control the pathogen.

\section{Transmission of SARS-CoV-2}

The principal mode of transmission of $\mathrm{CoV}$ is via droplets in coughs and sneezes, and close person-to-person contact. If a CoV finds its way to a food surface, some data suggest that the virus has a limited survival rate, unless there is optimum moisture, secure porous anchor site, and a virus-friendly temperature. Its viability will likely be a few hours to possibly several days. For example, using a bovine coronavirus (BCoV), which is a distant relative to SARS-CoV, as the infectious agent applied to Romaine lettuce stored at refrigeration temperature $(4 \mathrm{C}$ ) indicated viral plaques could be recovered after 25 days. (Ghana Health Service, 2018).

Zoonosis Transmission: Zoonoses or zoonotic diseases are infectious illnesses caused by bacteria, viruses and other pathogens that spread or 'spill' between animals and human. Approximately $75 \%$ of such infectious diseases among humans are manifested via animal spillover to humans. The WHO emphasizes the importance to control zoonoses which are often neglected, especially among populations living in poverty and rely on livestock.15 Except for the emerging zoonoses such as SARS and avian influenza H5N1, "the vast majority are not prioritized by health systems at national and international levels; therefore, are labelled as neglected." (Vision, 2014).

Zoonosis with CoVs are well established - civets (nocturnal mammals native to Asia and Africa) in the case of SARS and camels in the case of MERS. Given the similarity of SARS-CoV-2 with bat-associated SARS-CoV, it is likely that bats serve as the animal reservoir.2 Some CoVs that originated in pangolins (anteaters) have a receptor binding domain (RBD) similar to SARS-CoV-2. In that way, a pangolin either directly or indirectly involved in spilling its virus onto a human host.

Person-to-person Transmission: Person-to-person spread is the main mode of SARS-CoV-2 transmission, like other respiratory viruses such as influenza. The virus spreads from person-to-person through invisible droplets of water that are suspended in the air after a sick individual sneezes or coughs. Anyone within 6-feet (1.8 meters) radius of an infected person is at risk. Since genetic bottlenecks for RNA viruses often occur during respiratory droplet transmissions, the SARS-CoV-2 is expected to become less virulent through human-to-human transmissions.17

\section{COVID-19: Foodborne Infection and Transmission}

$\mathrm{CoV}$ infections are known in production animals such as scours and winter dysentery in beef and dairy cattle, respiratory CoVs in swine and avian infectious bronchitis in poultry. Transmission of animal-CoV to humans was evident during SARS and MERS outbreaks. Similar zoonotic involvement (bats and pangolins) has been suspected with the current COVID-19 pandemic. Therefore, further studies are needed prior to ruling out any potential food safety risk of production animals in the transmission of SAR-CoV2. 
Meat foods (beef, pork poultry, seafood, etc.) are rich in heparan sulfate (glycosaminoglycans), which are highly charged anchors for SARS-CoV-2 to interact with host tissue epithelia.9 Considering the survival of this viral pathogen for days on inanimate surfaces such as cardboard, plastic and stainless steel, it is obvious that animal (meat) tissue surfaces may be critical basements for foodborne transmission of COVID-19. Additional studies are warranted to evaluate the possible foodborne transmission of COVID-19 via meat foods and food processing.

\section{COVID-19: Food Contamination and Pathogen Survival}

Food Processing (Inanimate surfaces): In contrast to the respiratory microbes, enteric viruses such as noroviruses and hepatitis-A survives for weeks on surfaces, endure extreme temperatures and spread through contaminated foods. COVID-19 cannot survive for extended time on surfaces. Unlike bacteria, viruses cannot proliferate in food; therefore, the viral load is expected to dwindle over time, rather than increase in numbers. An analysis of 22 studies revealed that human $\mathrm{CoV}$ can persist on inanimate surfaces such as metal, glass or plastic for up to 9 days. Surface disinfection with $0.1 \%$ sodium hypochlorite (bleach), $0.5 \%$ hydrogen peroxide or $62-71 \%$ ethanol could significantly reduce CoV infectivity on surfaces within 1 min exposure. A similar effect against the SARS-CoV-2 is expected. A recent study reported that SARS-CoV-2 could remain viable in the air for up to 3 hours, on copper for up to 4 hours, on cardboard up to 24 hours, on plastic and stainless steel up to 72 hours. (Larson et al., 2011).

Also, SARS-CoV could be inactivated by ultraviolet light, thermal exposure (65 C), alkaline $\mathrm{pH}(>12)$ or acidic $\mathrm{pH}(<3)$ milieu. These data support the importance of cooking or processing foods to minimize the risk of SARS-CoV-2 transmission via a potentially contaminated food supply. Food Handling (Personnel): It is possible that CoV could hitchhike onto hands from contaminated surfaces during food handling. An individual could be exposed to COVID-19 by touching a contaminated surface or object and subsequently self-infect via oral, nasal or optic routes. However, this is no means the common mode of $\mathrm{CoV}$ transmission. Though certain individuals may become infected, SARS-CoV-2 is fairly a 'susceptible' virus. In theory, ingested CoV cannot survive the stomach acid. On tissue surfaces including skin, it can be easily removed by handwashing with soap, and eliminated using alcohol-based hand sanitizers. (Wittenberg et al., 2020) As a proactive approach, follow the 4 key steps of food safety - Clean, Separate, Cook, and Chill, to prevent foodborne illness.

\subsection{Food Safety Guidelines}

\subsubsection{Risk Management and Future Considerations}

In view of risk management, the CDC, the USDA, and the European Food Safety Authority (EFSA), have stated that there is lack of evidence to support the spread of COVID-19 through food or food packaging. (Ul Haq et al., 2012). Previous $\mathrm{CoV}$ outbreaks likewise showed no evidence of viral spread through food or packaging. However, these results also suggest that the infectious virions are released into the gastrointestinal tract, thereby suggesting the possibility of fecaloral transmission of SARS-CoV-2. This further emphasizes the importance of personal hygiene and sanitation guidelines to protect against COVID-19 infections.

\subsubsection{Viral testing and food protection?}

There are many biohazards associated with the food supply. The emergence of COVID-19 represents another challenge in assuring that the food supply remains safe. Viral contaminated oysters and orange juice that impacted Australia more than 20 years ago. (Vision, 2014). The authors noted that few food laboratories were prepared to analyze food products for viruses, and called for implementation of HACCP principles directed to specific risks associated with viruses, such as Norwalk-like viruses, rotavirus, astroviruses, adenoviruses, human caliciviruses, and parvovirus-like particles. A few years later, several investigators called for HACCP plans applied to aquaculture products, such as shrimp facilities. Throughout the United States, the seafood industry established an array of HACCP protocols. Even though these protocols acknowledge viruses as biological hazards, and that all domestic and imported fish and fishery products must comply with provisions of the Hazard Analysis Critical Control Point (HACCP) regulation for Fish and Fishery Products, the US regulatory agencies have stated that humans do not contract the coronavirus by eating seafood or other animal products. (Adekanle et al., 2015).

\subsection{Current COVID-19 Resources for Food Safety}

There are several credible resources at the intersection of COVID-19 and food safety. Some of these are listed in the following Table 1. 
Table 1 Valuable Credible Resources and Updates on COVID-19 and the Food Supply

\begin{tabular}{|ll|}
\hline Organization & URL \\
\hline World Health Organization (WHO) & https://www.who.int/emergencies/diseases/novel-coronavirus-2019 \\
\hline $\begin{array}{l}\text { U.S. Food and Drug Administration } \\
\text { (FDA) }\end{array}$ & $\begin{array}{l}\text { https://www.fda.gov/emergency-preparedness-and-response/mcm- } \\
\text { issues/coronavirus-disease-2019-covid-19 }\end{array}$ \\
\hline $\begin{array}{l}\text { Centers for Disease Control and } \\
\text { Prevention (CDC) }\end{array}$ & https://www.coronavirus.gov \\
\hline $\begin{array}{l}\text { USDA Animal and Plant Health } \\
\text { Inspection Service (APHIS) }\end{array}$ & https://www.usda.gov/coronavirus \\
\hline $\begin{array}{l}\text { European Food Safety Authority } \\
\text { (EFSA) }\end{array}$ & $\begin{array}{l}\text { https://www.efsa.europa.eu/en/news/novel-coronaviruswhere-find- } \\
\text { information }\end{array}$ \\
\hline Institute of Food Technologists & https://www.ift.org/about-ift/novel-coronavirus-updates \\
\hline
\end{tabular}

\section{Conclusion}

Understanding virus epidemiology is not a simple matter; confusion seems to have arisen because the coronaviruses typically evolve genetically and spillover from animal reservoirs to human hosts. The exact mechanism for this jump between species is not well-understood, but it does appear to occur in very crowded environments in which livestock or wild animals and humans are virtually on top of one another. Emerging data suggest fecal-oral spread, in addition to droplet or gas clouds created by coughs an sneeze, must be carefully controlled and monitored. The food supply chain is diverse throughout the US, and any disruptions in food supply during this crisis should be temporary as distribution catches up with demand. Importantly, as noted by the FDA, there is no evidence associating food or food packaging with the transmission of SARS-CoV-2.

\section{Compliance with ethical standards}

\section{Acknowledgments}

Thanks to Prof. David Ugal for proper review of our paper to increase clarity and scholar quality

\section{Disclosure of conflict of interest}

The authors declare that there is no conflict of interest regarding the main research, authorship and publication of this paper.

\section{References}

[1] Adekanle O, Ndububa DA, Olowookere SA, Ijarotimi O, Ijadunola KT. Knowledge of Hepatitis B Virus Infection, Immunization with Hepatitis B Vaccine, Risk Perception, and Challenges to Control Hepatitis among Hospital Workers in a Nigerian Tertiary Hospital. Hepatitis Research and Treatment. 2005.

[2] Chan JHL, Ma CC. Public health in the context of environment and housing. Primary Care Revisited: Interdisciplinary Perspectives for a New Era. April 2020; 295-310.

[3] Ghana Health Service. The Health Sector in Ghana: Facts and Figures 2018. Ministry of Health, Ghana. 2018; 150 .

[4] Kamboj S, Gupta N, Bandral J, Gandotra G, Anjum N. Food safety and hygiene: A review. International Journal of Chemical Studies. 2020; 8: 358-368.

[5] Larson HJ, Cooper LZ, Eskola J, Katz SL, Ratzan S. Addressing the vaccine confidence gap. In the Lancet. 2011.

[6] Olaimat A, Shahbaz H, Fatima N, Munir S, Holley R. Food Safety During and After the Era of COVID-19 Pandemic. Frontiers in Microbiology. 2020; 11: 1854. 
[7] Ul Haq N, Hassali MA, Shafie AA, Saleem F, Farooqui M, Aljadhey H. A cross sectional assessment of knowledge, attitude and practice towards Hepatitis B among healthy population of Quetta, Pakistan. BMC Public Health. 2012.

[8] Vision GI. MINISTRY OF HEALTH - GHANA Immunization Programme Comprehensive Multi - year Plan In line with Global Immunization Vision and Strategies. BMC Nephrology. 2014.

[9] WHO. Accelerating efforts on food safety Report by the Director-General. 1November 2019; 1-5.

[10] Wittenberg GM, Stylianou A, Zhang Y, Sun Y, Gupta A, Jagannatha PS, Wang D, Hsu B, Curran ME, Khan S, Vértes PE, Cardinal R, Richardson S, Leday G, Freeman T, Hume D, Regan T, Wu Z, Pariante C, Drevets WC. Effects of immunomodulatory drugs on depressive symptoms: A mega-analysis of randomized, placebo-controlled clinical trials in inflammatory disorders. Molecular Psychiatry. 2020; 25(6): 1275-1285. 